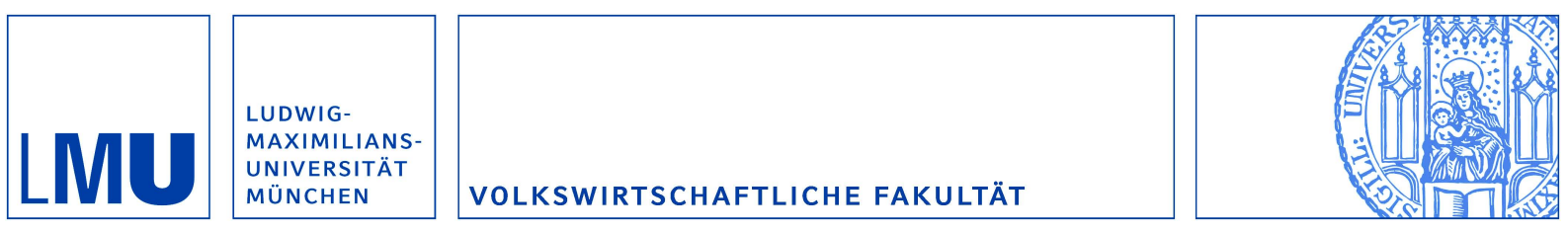

Schmidt, Klaus M.; Spann, Martin und Zeithammer, Robert:

Pay What You Want as a Marketing Strategy in Monopolistic and Competitive Markets

Munich Discussion Paper No. 2012-33

Department of Economics

University of Munich

Volkswirtschaftliche Fakultät

Ludwig-Maximilians-Universität München

Online at https://doi.org/10.5282/ubm/epub. 14308 


\title{
Pay What You Want as a Marketing Strategy in Monopolistic and Competitive Markets
}

\author{
Klaus M. Schmidt ${ }^{\text {a) }}$, Martin Spann ${ }^{\text {b) }}$, and Robert Zeithammer ${ }^{\text {() }}$
}

December 18, 2012

to be submitted to Management Science (Behavioral Econ. Dpt.)

\begin{abstract}
Pay What You Want (PWYW) can be an attractive marketing strategy to price discriminate between fairminded and selfish customers, to fully penetrate a market without giving away the product for free, and to undercut competitors that use posted prices. We report on laboratory experiments that identify causal factors determining the willingness of buyers to pay voluntarily under PWYW. Furthermore, to see how competition affects the viability of PWYW, we implement markets in which a PWYW seller competes with a traditional seller. Finally, we endogenize the market structure and let sellers choose their pricing strategy. The experimental results show that outcome-based social preferences and strategic considerations to keep the seller in the market can explain why and how much buyers pay voluntarily to a PWYW seller. We find that PWYW can be viable in isolation, but it is less successful as a competitive strategy because it does not drive traditional posted-price sellers out of the market. Instead, the existence of a posted-price competitor reduces buyers' payments and prevents the PWYW seller from fully penetrating the market. If given the choice, the majority of sellers opt for setting a posted price rather than a PWYW pricing. We discuss the implications of these results for the use of PWYW as a marketing strategy.
\end{abstract}

Keywords: customer-driven pricing mechanisms; pay what you want; revenue management; price discrimination; social preferences.

\footnotetext{
*) Financial support from the Excellence Initiative of the German government through MELESSA is gratefully acknowledged.

a) Klaus M. Schmidt, Department of Economics, University of Munich, D-80539 Munich, Germany, email: klaus.schmidt@1mu.de

b) Martin Spann, Munich School of Management, University of Munich, D-80539 Munich, Germany, email: spann@spann.de

b) Robert Zeithammer, The Anderson School of Management, UCLA, Los Angeles, USA, email: robert.zeithammer@anderson.ucla.edu
} 


\section{Introduction}

In several industries - including museums, software, and charity sales - some sellers use a marketing strategy that lets buyers pay what they want for the goods or services provided. The band Radiohead used it to sell a new music album online; restaurants in London, Berlin, and other cities let their buyers pay what they like for lunch; a theatre near Frankfurt tried it for generating revenue from movie screenings (Kim et al. 2009); and an amusement park in California did the same for souvenir photos (Gneezy et al. 2010). Profit results were mixed, ranging from a reported success for Radiohead to a loss for the movie theatre. But in all cases, many customers were willing to pay positive prices voluntarily, and some sellers have been using PWYW profitably for many years now.

In this paper, we report on several induced-value laboratory experiments identifying causal factors that determine buyers' willingness to pay voluntarily for a product. Furthermore, to see how competition affects the profitability and viability of PWYW, we implement markets in which a PWYW seller competes with a traditional seller offering posted prices. Finally, we endogenize the market structure and let sellers choose which pricing strategy to employ. In the experiments, several buyers are matched with one or two sellers to form a market. Endogenizing the market structure allows us to observe both the seller's choice to engage in PWYW pricing, as well as the buyers' subsequent purchasing and payment decisions. Each potential market persists for a publicly announced finite number of rounds. By considering what happens under different market scenarios, we analyze how the interaction of buyers and sellers affects the profitability and viability of PWYW, and how the market structure is formed endogenously. Our results have important implications for when sellers can use PWYW profitably.

There are three main reasons proposed in the literature for why PWYW can be an attractive pricing strategy. First, PWYW is a means of endogenous price discrimination because different consumers pay different prices for the same product even though no exogenous constraints are imposed on them. Customers who are fair-minded pay more than customers who are selfish, and a fair-minded customer may pay a higher price the higher his valuation for the product or the higher the seller's production costs. Furthermore, PWYW has a potential advantage over more traditional price discrimination methods because no reference price is posted. A buyer may not be willing to pay a high price for a product if he sees that the same product is sold at a much lower price to other customers or at another time or place. PWYW avoids this problem because it does not set a reference point. However, to effectively use PWYW as a price discrimination mechanism one has to better understand why buyers pay at all and what affects how much they pay voluntarily. There are several recent theories of social preferences that offer different explanations for voluntary payments. Outcome-based models of social preferences (such as altruism and inequity aversion) give rise to different predictions on the functioning and viability of PWYW than models of intention-based reciprocity. Our experiments test which factors have a causal effect on the prices paid voluntarily by consumers in anonymous 
PWYW markets. More specifically, we find that higher production costs of the seller and higher valuations of buyers induce higher voluntary payments, which are consistent with outcome-based models of social preferences. However, we find a lot of heterogeneity in behavior between subjects. We also find that repeated interactions between the same seller and buyers induce selfish buyers to pay positive prices to keep the seller in business. This finding is consistent with reputation models of cooperation in finitely repeated games with incomplete information (e.g., Kreps et al. 1982).

Second, some research claims PWYW is attractive for firms that want to maximize unit sales (Gneezy et al. 2010). Sales maximization is a natural objective for many non-profit organizations (such as museums or churches), but it is also the objective of some commercial firms that want to make profits from selling a complementary product, enter a new market, realize experience curve gains, or achieve network effects. PWYW supposedly dominates giving away the product for free because it generates positive revenues that cover at least some of the production cost. However, some field evidence (Gneezy et al. 2012) shows that people buy more at a posted price than if the product is offered using the PWYW mechanism, so PWYW may not maximize sales after all. Our experiments show that PWYW achieves almost full market penetration if the product is offered only by a PWYW seller, but not if a competing seller is using posted prices.

Third, PWYW can be used as a competitive strategy. PWYW effectively undercuts all sellers using posted prices and thus threatens to drive them out of the market. Furthermore, if only PWYW sellers remain in the market, PWYW softens competition because sellers no longer compete on price. On the other hand, competing sellers using posted prices could negatively affect the profitability of PWYW. These posted prices could form an upper bound on the prices that buyers are willing to pay voluntarily (Gneezy et al. 2012). Furthermore, some buyers may prefer to buy from a seller offering posted prices rather than enter moral deliberations about how much he ought to pay voluntarily. Our experiments show the conditions under which PWYW is viable as a competitive strategy. We do not find evidence of PWYW sellers driving posted-price sellers out of the market. Instead, both sellers in an otherwise undifferentiated duopoly tend to use posted pricing when we allow them to select their pricing model. When we assign pricing models, PWYW sellers make lower profits than their posted-price competitors, largely because the posted price does indeed seem to act as an upper bound on the PWYW payments.

Before introducing our results, we now briefly outline our experimental design. We induce different valuations for the buyers and different production costs for the sellers. A group of buyers and one seller or two sellers form one market and interact repeatedly for five periods in a row. Sellers can decide whether to make a costly investment in the quality of their product, which doubles buyers' valuations for it. In the base (monopoly) treatment, one seller has to use PWYW while interacting with three buyers for five periods in a row. In each period, the seller decides whether to enter the market and whether to invest in the quality of his 
product. In the competition treatments, we have two sellers interacting with six buyers. In the competition treatment with fixed roles, one seller has to offer a posted price while the other seller has to use PWYW. In the competition treatment with flexible roles, sellers can choose their pricing method and the market structure is determined endogenously.

Our subjects interact anonymously via a computer network with no scope for personal interactions. No complementary products exist for which PWYW can act as a loss-leader promotion tool, nor are network effects or learning-by-doing effects present that would make the seller interested in maximizing sales early in the product lifecycle. Therefore, our design is conservative in that it deliberately makes the profitability of PWYW difficult. Any profitability we find can thus be considered a lower bound of profitability in the real world, where buyers interact in person and long-run profit maximization may entail some short-run maximization of market share.

Despite the conservative design, we find that almost all potential sellers who can choose between entering the market with PWYW pricing or staying out actually enter, invest in the quality of their products, and make positive profits. Almost full market penetration occurs under monopolistic conditions. Some buyers take the product and pay nothing, but most buyers are willing to pay positive prices. We identify two reasons for why positive payments are made: First, buyers pay more the higher their own valuation for the product and the higher the seller's cost, but they do not react to the investment of the seller per se. This finding is consistent with theories of outcome-based social preferences such as altruism (Andreoni and Miller 2002) and inequity aversion (Fehr and Schmidt 1999) but not with theories of intention-based reciprocity (Rabin 1993). Second, some buyers pay positive prices in the early periods of the game to keep the seller in business, but they do not pay in the last period. This finding is consistent with reputation models (Kreps et al. 1982) in finitely repeated games with incomplete information, whereby self-interested buyers mimic the behavior of altruistic or fair-minded buyers in the early period of the game.

Competition significantly alters the picture. If a competing seller is offering the product at a posted price, market penetration of a PWYW entrant is no longer perfect. A significant fraction of buyers turns to the seller offering posted prices. This finding is consistent with the hypothesis that some people dislike deciding on voluntary contributions but also with some models of outcome-based social preferences. Furthermore, with competition, the prices that buyers pay voluntarily are significantly lower than under monopolistic conditions. In fact, the posted price of the competing seller seems to limit the amount that buyers are willing to pay voluntarily. Even though PWYW attracts a larger market share, posted-price selling is significantly more profitable. When sellers can decide which pricing method to use, the large majority opts for posted prices. Thus PWYW is not successful as a competitive strategy. Nevertheless, if the seller is interested in maximizing sales at the expense of profitability, then PWYW can be attractive even under competitive conditions. 
Our paper is related to three strands of the literature. First, it is related to a small empirical literature on PWYW pricing. Several field studies describe and analyze cases in which PWYW has been implemented in practice, including the rock band Radiohead and the Magnatune record label (Regner and Barría 2009), the Google answer service (Regner 2009), restaurants, snack bars, and cinemas (Kim, Natter and Spann 2009, 2010; Riener and Traxler 2012), and sales campaigns of hotels and travel agencies (Gautier and van der Klaauw 2012; León, Noguera, and Tena-Sánchez 2012). Gneezy, Gneezy, Nelson, and Brown (2010) conducted a field experiment on the sale of photos in an amusement park, showing that people pay much more if the PWYW seller announces that half of the revenues will be donated to charity. Our paper is the first to use a laboratory experiment to identify the causal effects that determine voluntary payments under PWYW, and to study the potential of PWYW as a competitive strategy. The only other laboratory experiment on PWYW pricing that we are aware of is Mak et al. (2010), who focus on how communication among participants affects payments.

Second, our paper is related to the experimental literature on trust games (Berg, Dickhaut, and McCabe 1995). In a trust game, the first mover has to decide whether to make an "investment" that benefits the second mover. Then the second mover has to decide whether to voluntarily return some of this benefit to the investor. For example, Fehr et al. (2007) consider the use of voluntary bonus payments in an experimental labor market. A worker decides how much effort to invest, which increases the gross profit of his employer. The employer observes the worker's effort and decides on a voluntary bonus payment for the worker. Even though the interaction is one-shot, many employers reciprocate to high effort with high bonus payments. This response in turn induces many workers to spend high effort. Our experiment has a similar but richer structure and is adapted to the PWYW context. In particular, one seller deals with several buyers, raising the possibility of free-riding. In addition, we vary costs and benefits of the parties, and the interaction is finitely repeated. ${ }^{1}$

Finally, our paper is related to the theoretical literature on social preferences that tries to explain prosocial behavior (see Fehr and Schmidt 2006, for a survey). If all people were only concerned about their own material payoffs, nobody would ever pay a positive price if the PWYW pricing mechanism were used (this prediction also holds in all of our experimental treatments because of the finite number of repeated interactions). However, substantial experimental and field evidence now exists that shows that many people are also concerned about fairness and reciprocity and are willing to sacrifice own resources to achieve a more equitable allocation. Several theories try to explain the observed behavior, including altruism (Andreoni and

\footnotetext{
${ }^{1}$ An experimental literature also exists on reputation mechanisms based on repeated interaction (e.g., Brown et al. 2004) and on customer ratings as provided by eBay or Amazon (e.g., Bolton et al. 2004). Here a seller has an incentive to deliver high quality in order to keep a good reputation. A seller who succumbs to the temptation to deliver low quality loses his reputation and is out of business in future periods. In PWYW markets, customers not only decide whether to buy or not, they also decide the price. Thus they can punish the seller for delivering low quality by taking his product and paying zero, which is even more costly to the seller than losing a customer. On the other hand, customers have to actively support the seller by paying positive prices voluntarily if they want to keep him in business.
} 
Miller 2002), inequity aversion (Fehr and Schmidt 1999; Bolton and Ockenfels 2000), and intention-based reciprocity (Rabin 1993; Dufwenberg and Kirchsteiger 2004). Moreover, prior work finds substantial population heterogeneity in individual social preferences (Andreoni and Miller 2002), giving rise to incomplete information each seller possesses about the preference types of the particular buyers he faces. We discuss the specific implications of the different theories for PWYW behavior within our experiments in more detail in section 2.

The remainder of this article is organized as follows. In the next section, we discuss in more detail the three main reasons for using PWYW, relate them to the theoretical literature on social preferences, and derive predictions that we test in the experiments. Section 3 outlines our experimental design and describes the experimental procedures. The results of the experiments and the tests of the predictions are discussed in section 4. Section 5 concludes.

\section{Theory and Predictions}

Why would a seller choose to offer his products using the PWYW pricing strategy? How do sellers and buyers react to different costs, valuations, and market structures? In this section, we discuss three main reasons this strategy might be attractive to sellers, and derive several behavioral predictions that can be tested experimentally.

\subsection{Price Discrimination}

PWYW is a price-discrimination mechanism whereby different consumers pay different prices for the same product. Customers who are fair minded pay more than customers who are selfish, and the higher their valuation for the product and the higher the seller's production costs, the more fair-minded customers pay. With PWYW, price discrimination is endogenous in the sense that the seller does not exogenously impose different prices on different types of buyers or on different choices of buyers. It arises endogenously from the buyers' unconstrained behavior. Furthermore, PWYW has a potential advantage over other pricediscrimination methods. A buyer may not be willing to pay a high price for a product if he sees the same product is sold at a much lower price to other customers or at another time or place. PWYW avoids this problem because it does not set a reference point. Thus it price discriminates without influencing consumers' reference prices.

But why would a buyer pay any positive amount if he is not required to do so? The traditional selfinterest model predicts that all buyers will take the product and pay a price of zero. Even if there is a (finitely) repeated relationship and buyers are interested in purchasing the product in several periods, a standard 
backward-induction argument implies that the market unravels, that buyers never pay and that a PWYW seller will never enter the market.

Theories of prosocial behavior predict that some buyers pay a positive amount voluntarily in a PWYW setting, but they differ in their explanations for why buyers do so, and they come up with different predictions under what conditions people are willing to pay more. Understanding which theory drives behavior has important implications for the use of PWYW as a price-discrimination mechanism and for its overall viability. Theories of prosocial behavior can be grouped into three broad classes, as follows:

a) Outcome-based theories of social preferences such as altruism (Andreoni and Miller 2002) or inequity aversion (Fehr and Schmidt 1999) argue that many people are not purely self-interested but also care about the well-being of others. They are willing to give up own resources to help someone else, especially if the other person is worse off than they are. These models predict that the larger the buyer's benefit from consuming the product and the higher the seller's cost of production, the higher the payments will be. In other words, PWYW pricing involves price discrimination and at least partial compensation of the seller. As long as other-regarding preferences are strong enough, buyers should pay strictly more than the seller's marginal cost whenever their valuation is high enough, and forego a purchase otherwise. Beyond the scope of our experimental variation, the outcome-based models also predict that people are willing to pay more to a non-profit organization or to a firm that is small and poor than to a large and rich corporation.

b) Intention-based models of reciprocity (e.g., Rabin 1993; Dufwenberg and Kirchsteiger 2004) are based on the hypothesis that some people reciprocate to kind intentions that are expressed by kind actions. For example, if the seller chooses to offer his product using PWYW or if he makes a special investment that increases the value of the product to the buyer, then such an action is interpreted as an act of kindness that the buyer is willing to reciprocate by paying a higher price. According to these theories, the buyer's payment does not depend on the wealth of the seller or on exogenous variations of costs and benefits, but rather on the actions taken by the seller. Thus these models predict that if the seller takes an action that is beneficial to the buyer, for example, making a special effort to increase the quality of the product or the service, then a buyer who is more strongly motivated by reciprocity will react by paying a higher price, but he will not pay more if his valuation increases for reasons that are unrelated to the seller's actions.

c) Reputational models (e.g., Kreps et al. 1982) of finitely repeated games with incomplete information can explain why even purely self-interested buyers have an incentive to pay positive prices in early periods, as long as there are some fair-minded or reciprocal buyers who pay positive prices in all periods (including the last period). If the seller has incomplete information about the type of the buyer, self-interested buyers want to build up a reputation for paying positive prices that cover the seller's cost in order to keep the seller in business. The seller anticipates this behavior and is willing 
to enter and stay in the market. In the last few periods, a self-interested buyer randomizes whether to pay or pay not, whereas a fair-minded and reciprocal buyer continues to pay a positive price with probability one. These models predict that average prices should decline when the market comes to an end. They also predict that buyers pay higher prices if the seller's costs go up (to keep him in business), but not if their own valuation increases. Furthermore, they predict that if a competing traditional seller is present (offering the product by posting a price), then selfish buyers have a much smaller incentive to keep the PWYW seller in business, so the price they pay in early rounds will be lower. The reduced incentive suggests that PWYW is more likely to be viable under monopolistic than under competitive conditions.

Note that models of outcome-based social preferences as well as models of intention-based reciprocity and reputational models all assume heterogeneity in social preferences, so the three classes of models discussed above are not mutually exclusive. They give rise to the following three predictions.

Prediction: PWYW achieves price discrimination as long as one of the following mechanisms applies:

(P1a) PWYW induces customers with outcome-based social preferences to pay more the higher their valuation and the higher the seller's cost.

(P1b) PWYW induces customers motivated by intention-based reciprocity to pay more if the seller invests in the quality of his product.

(P1c) PWYW induces self-interested customers in early rounds to pay higher prices if the cost of the seller is higher, in order to keep the seller in business. However, this incentive vanishes in the last period of each block or if a competing seller is offering the same product.

We know from the empirical literature and from several case studies that PWYW does achieve some price discrimination (e.g., Kim et al. 2009), but this literature cannot distinguish the reasons why price discrimination works. In an experimental study, we can change the parameters of the market exogenously and thereby identify causal effects for the behavior of buyers. Thus we can test which of these three forces drives buyers' behavior and what their relative importance is. Our findings provide important insights regarding the conditions under which PWYW is most likely to be a successful price-discrimination strategy.

\subsection{Market Penetration}

In some situations, firms are more interested in maximizing unit sales rather than in maximizing profits. For example, non-profit organizations such as museums or churches typically want to attract as many "customers" as possible. Sales maximization also appeals to sellers who want to promote a complementary 
product, particularly if the (traditional) sale of the complementary product is highly profitable. For example, for the British rock band Radiohead, some argue that offering its album "Rainbows" on the internet by using the PWYW mechanism dramatically increased the popularity of the album and thereby increased the profits from the (traditional) sale of the $\mathrm{CD}$ and the concert tour. ${ }^{2}$ Furthermore, maximizing sales may appeal to a seller who wants to enter a new market, test a new product, generate network effects, or realize learning-bydoing effects.

PWYW seems to be an ideal strategy for maximizing market penetration. Of course, one can also achieve maximal market penetration by simply giving away the product for free. In fact, this is what many companies do. ${ }^{3}$ The advantage of PWYW is that it makes the product available to everybody free of charge, but it also generates positive revenues if some buyers pay positive prices voluntarily. As long as the potential transaction is efficient (as will be the case in our experimental design), models from all three classes of theories discussed above imply the buyers will buy the product, and hence we can make the following prediction:

Prediction P2: When the potential trade between the seller and the buyers is efficient, PWYW is a strategy that achieves maximal market penetration.

Unlike the predictions about price discrimination, this prediction holds even when all buyers are purely selfinterested. We note that when the potential transaction is not efficient (i.e., the seller's marginal cost is strictly higher than the buyer's valuation), the three classes of models do not come up with a clear-cut prediction about market penetration. ${ }^{4}$ However, in only 22 out of 2636 cases in all treatments of our experiment does the seller enter and offer PWYW, and a buyer's valuation is smaller than the seller's cost.

Even in markets with efficient potential trades, PWYW may not achieve maximal market penetration whenever buyers experience additional friction costs that our theoretical development does not consider. For example, a customer may feel uneasy about taking a product without knowing what he ought to pay. In fact, Gneezy et al. (2012) report on three field experiments showing that more people buy the product if it is offered at a fixed price than if the PWYW mechanism is used. They argue that concerns for self-image and

\footnotetext{
${ }^{2}$ http://www.wired.com/entertainment/music/magazine/16-01/ff_yorke?currentPage=all.

${ }^{3}$ Examples include internet service providers (such as Google) or media (such as radio and TV stations) that offer their services for free to one side of the market and sell complementary products (such as advertising) to the other side, or the government that offers public services (such as schools, roads, law enforcement, etc.) free of charge to users.

${ }^{4}$ In this case, parameters of the buyer's utility function exist such that the buyer refuses to trade if the transaction is inefficient. He does so to benefit the seller either because he is concerned about the seller's welfare, or because he wants to reciprocate the kindness of the seller by being so kind not to buy, or because he wants to keep the seller in the market.
} 
identity drive this behavior. People feel bad if they pay less than the "appropriate" price, which causes them not to buy the product at all. The existence of such concerns suggests that the lower a customer's valuation, the less likely he is to accept the product under PWYW. Furthermore, a customer may prefer to buy the product at a given price from a competing seller offering posted prices rather than enter moral deliberations about what price he ought to pay a PWYW seller.

In our lab experiment, we can control the willingness to pay for the product of each customer and we observe whether he buys the product and how much he pays voluntarily. Furthermore, we can compare behavior under monopolistic and under competitive conditions. Thus we can test how the reaction to PWYW is affected by these factors and whether and under what conditions PWYW is an effective market-penetration strategy.

\subsection{Competition}

PWYW can also be used as a competitive strategy. It can be either an aggressive or conciliatory strategy depending on the pricing format used by the competitor. PWYW is an aggressive strategy for competing with a posted-price seller because the PWYW seller offers to give away his products for free (i.e., below cost), which threatens to drive out traditional sellers from the market. If the posted-price seller does not get any customers, he has to either leave the market or adopt PWYW, as well. This incentive to respond in kind leads to the possibility of both sellers choosing to use PWYW in equilibrium.

When all sellers decide to use PWYW, then PWYW softens competition by eliminating price competition. Thus, if enough fair-minded or reciprocal buyers are willing to pay positive prices voluntarily and if production costs are low, then PWYW duopolists might achieve higher profits than posted-price duopolists engaged in fierce price competition. ${ }^{5}$ These two considerations give rise to our third prediction:

Prediction P3: PWYW is a competitive strategy that drives traditional posted-price (PP) sellers out of the market.

If only PWYW sellers are present, no price competition occurs. Thus, if costs are sufficiently small, using PWYW pricing is optimal for both sellers.

The first part of prediction P3 is an immediate implication of P2. However, in the discussion of prediction P2, we argued that P2 need not hold if concerns for self-image and identity affect behavior. In this

\footnotetext{
${ }^{5}$ This result is also predicted in a theoretical paper by Chen, Koenigsberg, and Zhang (2010), who consider the competitive implications of PWYW pricing in a horizontally differentiated duopoly. They confirm the above intuition by proving that when enough consumers care about distributive fairness, weaker horizontal differentiation results in more firms using PWYW to soften price competition.
} 
case, some customers may opt for the PP seller because they are happy to buy the product for a low posted price, but they would feel "cheap" if they paid this low price voluntarily. Thus, we have no guarantee that traditional sellers will be driven out of the market.

The second part of P3 is more likely to hold when enough buyers have outcome-based social preferences or exhibit intention-based reciprocity. Such buyers pay positive prices, no matter whether there are one or two PWYW sellers which may render PWYW profitable. Self-interested buyers, however, have no incentive to keep both sellers in the market. Even if one seller exits, a second one offering the same product is still present. Therefore, a PWYW duopoly is less likely to emerge when most buyers are self-interested, and PWYW sellers only receive positive payments thanks to reputational concerns in finitely repeated games. These arguments suggest PWYW is less viable in a competitive market than in a monopolistic situation.

Our last prediction concerns the nature of price competition between a PWYW seller and a PP seller. We propose that the posted price may act as an upper bound for prices that customers pay the PWYW seller. Why should a buyer pay more to the PWYW seller than what a traditional seller is charging as a posted price for the same product? Furthermore, as long as two sellers are present, buyers have less of an incentive to pay high prices voluntarily to keep the PWYW seller in the market. Therefore, we predict the following:

Prediction P4: If a PWYW seller competes with a posted-price seller and both types of sellers stay in the market, then the PWYW seller will get lower prices on average than if he is a monopolist.

In the experiment, we can test predictions $\mathrm{P} 3$ and $\mathrm{P} 4$ rigorously. In a first step, we impose the market structure exogenously to test P4 and see whether and under what conditions a PWYW seller drives a traditional seller out of the market. Then we endogenize the market structure to see whether sellers choose PWYW as a competitive strategy. In both treatments, we can compare the prices paid voluntarily to PWYW sellers to the prices paid in the treatment with a monopolistic PWYW seller. A nice feature of the experiments is that the unit of observation is the entire market; that is, we not only observe the reaction of buyers to PWYW, but we also observe the interaction of buyers and sellers and whether and under what conditions sellers choose to employ PWYW to market their products. 


\section{Experimental Design}

\subsection{Base Treatment}

The base treatment of the experiment considers one seller who faces three potential buyers, each of whom wants to buy one unit of the product to be produced by the seller. The seller is restricted to selling his product by using the PWYW mechanism; that is, each buyer can decide for himself what price to pay, including a price of zero.

At the beginning of each period (stage 1), the seller has to decide whether to enter the market. If he stays out, the period ends and the seller and the three buyers get a payoff of zero. If the seller enters, at stage 2 , he decides on an investment in the quality of his product. The investment costs the seller two points and doubles the valuation of the product for all buyers.

At stage 3, all players learn the seller's marginal cost of production and the buyers' valuations. The production cost $c \in\{0,1,2,3,4\}$ is drawn randomly. Each buyer $b \in\{1,2,3\}$ is assigned a base valuation $\underline{v}^{b} \in\{2,6,10\}$ that is also drawn randomly for each buyer. If the seller invested in a quality improvement at stage 2 , the valuations of all buyers are doubled. Thus the actual valuation of each buyer $b$ is $v^{b} \in\{2,4,6,10,12,20\}$. Finally, at stage 4 , each buyer decides whether to buy the product and what price $p^{b} \geq 0$ to pay. The seller is obliged to supply the product to every buyer who wants to buy it at the price $p^{b}$ the buyer pays voluntary.

\begin{tabular}{|c|c|c|c|}
\hline $\mathrm{t}=1$ & $\mathrm{t}=2$ & $\mathrm{t}=3$ & $\mathrm{t}=4$ \\
\hline $\begin{array}{l}\text { Seller decides } \\
\text { whether to } \\
\text { enter the } \\
\text { market }\end{array}$ & $\begin{array}{l}\text { Seller decides } \\
\text { whether to invest } \\
\text { into the quality of } \\
\text { his good }\end{array}$ & $\begin{array}{c}\text { Seller and buyers learn the } \\
\text { seller's marginal cost } c \text { and } \\
\text { each buyer learns his actual } \\
\text { valuation } \boldsymbol{v}^{b}\end{array}$ & $\begin{array}{c}\text { Buyers decide whether } \\
\text { to buy and which price } \\
\boldsymbol{p}^{b} \text { to pay. } \\
\text { Payoffs are made. }\end{array}$ \\
\hline
\end{tabular}

FIGURE 1.- Sequence of Events in Each Period: Base Treatment

Finally, payoffs are realized. The seller's monetary payoff is

$$
M^{s}=\left\{\begin{array}{cl}
0 & \text { if he did not enter the market } \\
\sum_{b=1}^{3} B^{b}\left(p^{b}-c\right)-2 I & \text { if he did enter the market }
\end{array},\right.
$$


where $B^{b} \in\{0,1\}$ and $I \in\{0,1\}$ are indicator variables with $B^{b}=1$ if buyer $b$ decided to buy and $I=1$ if the seller decided to invest. Note that the buyer incurs the marginal cost $c$ only if a buyer buys his product, whereas the investment cost of 2 is sunk and independent of the number of buyers. The monetary payoff of buyer $b$ is given by

$$
M^{b}=\left\{\begin{array}{cc}
0 & \text { if the seller did not enter or buyer } b \text { did not buy } \\
v^{b}-p^{b} & \text { if the seller entered and buyer } b \text { did buy }
\end{array} .\right.
$$

This game is repeated in a block of five periods with the same group of one seller and three buyers. Then sellers and buyers are randomly rematched and a new block of five periods starts. Each session has 20 periods divided into four blocks. Each subject keeps his role as a buyer or seller throughout the entire session, but valuations and costs are randomly reassigned in each period. Before the experiment starts, the instructions (see appendix) are read aloud to all subjects.

Note that the experimental design biases the results strongly against the PWYW mechanism. The interaction is computerized and completely anonymous. No scope exists for communication or personal interaction between the subjects. The product is fictitious and reduced to its monetary value for the buyer. All of these factors make it easy for a buyer to take the product and pay nothing.

The Base Treatment is designed to measure the causal effects of production costs and valuations on the buyers' purchasing decisions and on the prices paid voluntarily. We can test whether PWYW achieves full market penetration in a monopolistic situation where there is no alternative to buy the product from some other seller. Furthermore, because buyers and sellers interact repeatedly over five periods, we can test whether average prices decline over time within each block, which would indicate that some buyers are paying positive prices for strategic reasons in order to keep the seller in business.

\subsection{Exogenous Investment Treatment}

To specifically test for intention-based reciprocity as a driver of buyer payments, we conducted a control experiment in which the investment was imposed exogenously as follows: For two sessions of the base treatment, we conducted a new session with exogenous investments that exactly matched the seller investment behavior in the base treatment. ${ }^{6}$ Thus, for each period and each group of one seller and three buyers, we exogenously imposed the investment level that was chosen endogenously in the base treatment. Therefore, the valuations of the buyers are exactly the same in the two treatments, but in the base treatment, they have been determined by the voluntary investment decisions of the sellers while they have been assigned by the experimenter in the exogenous investment treatment. Furthermore, if a seller incurred the investment

\footnotetext{
${ }^{6}$ In the few instances in which the base treatment seller did not enter the market, his investment decision is unknown, and so we generated it randomly with the empirically correct probability.
} 
cost voluntarily in the base treatment, then the corresponding seller in the exogenous investment treatment was forced to incur the same investment cost. Thus the two treatments are identical except for whether the investment decision was taken voluntarily or imposed exogenously. If buyers pay significantly higher prices in the base treatment than in the exogenous investment treatment, then this is causal evidence for intentionbased reciprocity, with the investment decision being the "kind action."

\subsection{Competition: Fixed and Flexible Roles}

The treatments described so far consider a monopolistic seller. We also conducted two competition treatments. In these treatments, we had two sellers and six buyers in one group. At the beginning of each period, each of the sellers decides whether to enter the market. In the competition treatment with fixed roles (COMP_FIX), one of the two sellers had to use PWYW and the other seller had to post a price. In the competition treatment with flexible roles (COMP_FLEX), each seller chooses whether to use the PWYW mechanism or to post a price. In both treatments, buyers observe which sellers uses which pricing mechanism, whether a seller invested in the quality of his product, and what price (if any) is posted. If a buyer bought from the PWYW seller, he determined which price to pay. If he chose the seller with the posted price, he had to pay the posted price.

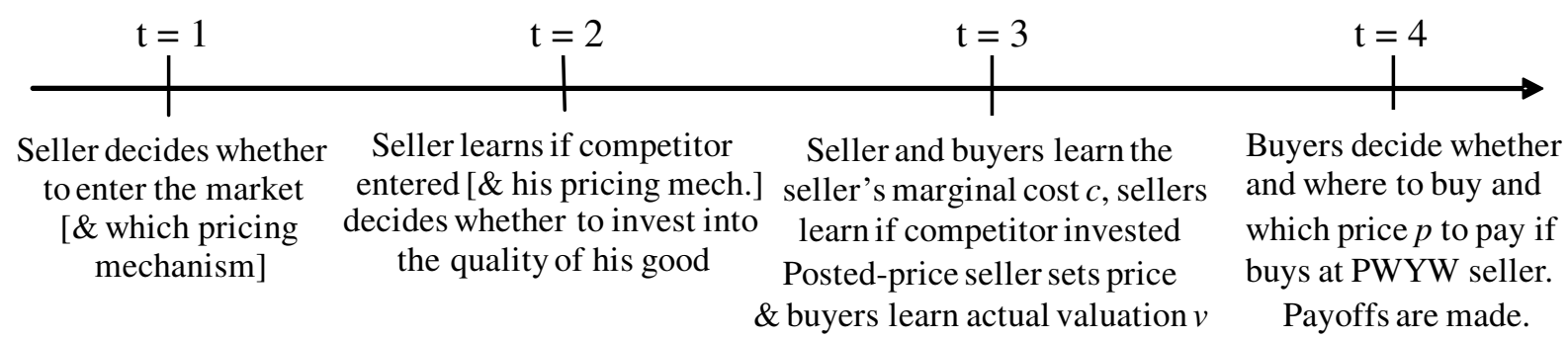

FIGURE 2.--Sequence of Events in Each Period: Competition Treatments

The competition treatments are designed to test the effect of competition on our behavioral predictions. If a competing seller is present, buyers have to be less concerned about keeping the PWYW seller in business and may pay less. Furthermore, we can test whether all buyers go to the PWYW seller and the traditional seller is driven out of the market. If the PWYW seller does not corner the market, then some other forces, such as concerns for self-image or inequity aversion, must be affecting behavior. Furthermore, the competition treatments allow us to see whether the price a traditional seller charges acts as a reference point that limits the prices paid voluntarily.

In COMP_FLEX, sellers could choose whether to use the PWYW mechanism or to post prices (PP). According to prediction P3, if one PWYW seller faces one PP seller, then the PWYW seller will get all 
consumers and the PP seller makes a profit of zero or a loss (if he invested). If both sellers offer posted prices, Bertrand competition will drive down prices to marginal costs, and profits are also (close to) zero or negative due to the sunk investment cost. Thus, offering posted prices does not seem to be attractive. Offering PWYW, on the other hand, eliminates price competition and appeals to consumers' fairness and reciprocity. If intention-based reciprocity drives consumers, they may behave even more reciprocally if the seller has chosen PWYW rather than been forced to use this pricing strategy as in COMP_FIX. These arguments suggest opting for PWYW may be a good idea.

On the other hand, if consumers are motivated by altruism or inequity aversion, they may also buy from a seller offering posted prices. In this case, PWYW need not push a PP seller out of the market. If the PP seller survives, prediction P4 suggests his price limits what buyers are willing to pay the PWYW seller voluntarily, which reduces PWYW profits. Furthermore, if most consumers are selfish and pay positive prices only for strategic reasons (to keep the PWYW seller in business), they have a much lower incentive to pay if they can rely on a second seller to supply the product. Again ${ }_{2}$ this argument works against the profitability of PWYW.

The competition treatments test these arguments experimentally. Because the unit of observation is an entire market, we can see how the interaction of buyers and sellers affects the profitability and viability of PWYW as a competitive strategy and how the market structure is formed endogenously.

We conducted the experiments at MELESSA of the University of Munich in 2010/11. We had four sessions for the base treatment, the exogenous investment treatment, and the COMP_FIX ${ }^{7}$ treatment, and two sessions of the control treatment and the COMP_FLEX treatment, with 24 participants in each session, for a total of 288 subjects participating in the experiments. Subjects were undergraduate students from the University of Munich and the Technical University of Munich studying a broad range of majors. Experiments were computerized using the software z-Tree (Fischbacher 2007) and ORSEE (Greiner 2004). Sessions lasted about two hours (including the completion of a questionnaire). On average, subjects earned about $€ 18.8$ (US\$26.40 at the time of the experiments), which includes a show-up fee of $€ 4$ (US\$5.60).

\section{Experimental Results}

We organize the presentation and discussion of our experimental results according to the three main reasons for using PWYW: price discrimination, market penetration, and competition.

\footnotetext{
${ }^{7}$ In the sessions of the COMP_FIX treatment, we had the subjects play two blocks of COMP_FIX followed by two of COMP_FLEX, which is why we have only two blocks in the COMP_FIX treatment. The observations of the COMP_FLEX treatment in blocks 3 and 4 are thus not directly comparable to the observations in the sessions with four blocks of COMP_FLEX. To be on the safe side, we use only the COMP_FLEX data of the sessions with four blocks of the COMP_FLEX treatment.
} 


\subsection{Price Discrimination}

Our first prediction is that PWYW is a means of endogenous price discrimination because different consumers voluntarily pay different prices for the same product. Thus we first need to test whether buyers make positive voluntary payments even in our setting that involves full anonymity and no personal interaction.

Result 1: In all treatments, a large fraction of buyers who buy from a PWYW seller make substantial voluntary payments. Mean PWYW prices are significantly above zero and above production costs in all treatments. On average, payments are sufficient to cover the seller's cost and to generate a small profit when sellers in quality. Without investment, profits are close to zero or negative. A lot of heterogeneity is present in buyers' behavior. In particular, a significant minority of buyers pays zero.

Support for Result 1 is provided in Table 1. Buyers pay on average a price of 3.1 in the base treatment and 3.5 in the exogenous investment treatment. With competition, prices are lower: 2.3 for the PWYW seller in the competition treatment with fixed roles and 1.7 in the treatment with flexible roles. A lot of heterogeneity is present in buyers' behavior. Although some buyers pay fairly generous prices, $19.3 \%$ of them pay zero in the base treatment $(21.5 \%$ in the exogenous investment treatment). With competition, this fraction increases significantly to more than one third of all buyers. However, in the monopoly treatments, the majority of buyers pay a voluntary price that is greater than the production cost of the seller. In all treatments, investing pays off and sellers make positive profits, but competition reduces profits. Without investment, profits are close to zero or negative.

\begin{tabular}{|c|c|c|c|c|c|}
\hline Treatment & BASE & BASE Match & EX. INVEST & COMP_FIX & $\overline{\text { COMP_FLEX }}$ \\
\hline PWYW buy ${ }^{\text {a) }}$ & $96.7 \%$ & $97.3 \%$ & $96.2 \%$ & $73.9 \%$ & $89.7 \%$ \\
\hline PWYW price ${ }^{b)}$ & 3.14 & 3.24 & 3.53 & 2.33 & 1.67 \\
\hline PWYW price invest ${ }^{\mathrm{b})}$ & 3.46 & 3.44 & 3.69 & 2.43 & 1.88 \\
\hline PWYW price no invest ${ }^{\mathrm{b})}$ & 1.47 & 1.40 & 2.04 & 0.32 & 0.68 \\
\hline Percent zero payment ${ }^{\text {b) }}$ & $19.3 \%$ & $20.0 \%$ & $21.5 \%$ & $34.8 \%$ & $43.0 \%$ \\
\hline Percent price $>$ prod. cost ${ }^{b)}$ & $62.3 \%$ & $64.7 \%$ & $66.3 \%$ & $49.8 \%$ & $39.1 \%$ \\
\hline PWYW Seller entry & $85.6 \%$ & $82.9 \%$ & $81.3 \%$ & $92.5 \%$ & $14.6 \%{ }^{c)}$ \\
\hline PWYW Seller invest & $83.5 \%$ & $89.9 \%$ & $90.3 \%$ & $86.5 \%$ & $77.1 \%$ \\
\hline PWYW Seller profit ${ }^{a)}$ & 2.76 & 3.09 & 3.56 & 1.83 & 0.37 \\
\hline PWYW Seller profit invest ${ }^{\text {a) }}$ & 3.31 & 3.55 & 3.90 & 2.22 & .96 \\
\hline PWYW Seller profit no invest ${ }^{a)}$ & 0.03 & -1.05 & 0.37 & -0.67 & -1.63 \\
\hline
\end{tabular}

TABLE 1.- Summary statics 
What determines how much buyers pay? Outcome-based theories of social preferences (P1a) predict buyers are motivated by concerns for fairness and equity and should therefore pay more if their own valuation and if the seller's cost increase. By contrast, intention-based models of reciprocity predict buyers pay more to reciprocate the seller for his investment in quality, whereas exogenous changes in valuations or costs have no effect (P1b). Prediction P1c suggests buyers are driven by the strategic concern to keep the seller in the market, so their payments should decline over time and drop to zero in the last period of each block.

Table 2 reports a regression of prices on these factors for each of the four treatments. We find that an increase in the valuation by one unit increases the price buyers pay by about 0.2 units in the monopoly treatments, but only by 0.1 units in the competition treatments. This effect is highly significant. Furthermore, an one-unit increase of the seller's cost significantly increases the buyer's voluntary payment by about 0.2 units in all treatments. ${ }^{8}$ This finding suggests a significant fraction of buyers is concerned about fairness and equity, which is consistent with P1a (outcome-based social preferences). However, only in the base treatment does the seller's investment decision exhibit an additional effect (that is just significant at the 5\% level) on the price buyers pay beyond the effect already captured by the increase in his valuation. Thus the regressions provide only limited support for $\mathrm{P} 1 \mathrm{~b}$, that is, intention-based reciprocity. We further find a significant lastperiod effect in the base treatment. Some buyers clearly make voluntary payments to keep the seller in the market, but withdraw their support in the last period. This effect is insignificant in the exogenous investment and the competition treatments. This finding is consistent with P1c. In the competition treatments, keeping the PWYW seller in the market is less important, because a competing seller also offers the product. Thus prices are lower with competition, and therefore the price reduction in the last round is also smaller. Further, we see that some learning effects occur in our experiments because prices in the first two blocks of the base treatment (and the first block of the COMP_FIX treatment) are (significantly) higher than in the last block. However, these results appear to stabilize over time (please note the third block of the monopoly base treatment does not yield significantly higher payments than the last block).

\footnotetext{
${ }^{8}$ The competition treatments are discussed in more detail in Section 4.3.
} 


\begin{tabular}{|c|c|c|c|c|c|}
\hline Treatment & $\begin{array}{c}\text { (1) } \\
\text { BASE }\end{array}$ & $\begin{array}{c}\text { (1') } \\
\text { BASE Match }\end{array}$ & $\begin{array}{c}(2) \\
\text { EX. INVEST }\end{array}$ & $\begin{array}{c}\text { (3) } \\
\text { COMP_FIX }\end{array}$ & $\begin{array}{c}(4) \\
\text { COMP_FLEX }\end{array}$ \\
\hline Intercept & $-0.18(0.26)$ & $-0.20(0.40)$ & $0.47(0.47)$ & $0.06(0.40)$ & $-0.08(0.35)$ \\
\hline Buyer valuation $^{\text {a) }}$ & $\mathbf{0 . 1 9}(0.02)$ & $\mathbf{0 . 1 8}(0.02)$ & $\mathbf{0 . 2 0}(0.03)$ & $\mathbf{0 . 1 2}(0.02)$ & $\mathbf{0 . 1 1}(0.03)$ \\
\hline Production cost & $\mathbf{0 . 2 8}(0.05)$ & $0.21(0.07)$ & $\mathbf{0 . 2 3}(0.09)$ & $\mathbf{0 . 2 8}(0.09)$ & $0.22(0.08)$ \\
\hline Seller investment (DV) & $\mathbf{0 . 3 4}(0.17)$ & $\mathbf{0 . 5 1}(0.22)$ & $0.16(0.23)$ & $0.09(0.39)$ & $0.03(0.23)$ \\
\hline Last round $(\mathrm{DV})^{\mathrm{b})}$ & $\mathbf{- 1 . 0 1}(0.23)$ & $\mathbf{- 0 . 6 8}(0.30)$ & $-0.66(0.33)$ & $-0.17(0.14)$ & $-0.44(0.32)$ \\
\hline Block1 (DV) ${ }^{\mathrm{c})}$ & $\mathbf{0 . 7 1}(0.20)$ & $\mathbf{0 . 7 7}(0.30)$ & $0.30(0.22)$ & $\mathbf{0 . 3 9}(0.15)$ & $0.49(0.25)$ \\
\hline Block2 (DV) ${ }^{\mathrm{c})}$ & $\mathbf{0 . 4 6}(0.15)$ & $\mathbf{0 . 7 1}(0.25)$ & $0.40(0.21)$ & d) & $0.23(0.32)$ \\
\hline Block3 (DV) ${ }^{\text {c) }}$ & $0.08(0.12)$ & $0.20(0.20)$ & $-0.24(0.21)$ & & e) \\
\hline No. of Obs. & 1,192 & 581 & 563 & 492 & 156 \\
\hline R-squared & 0.395 & 0.356 & 0.326 & 0.231 & 0.339 \\
\hline No. of Subjects & 72 & 36 & 36 & 72 & 36 \\
\hline
\end{tabular}

Notes: The dependent variable is measured in the experimental currency; only observations of buyers buying are included. FE regression with subject-specific fixed effects (robust standard errors in parentheses). Treatment (1'): base treatment, only sessions matched to exo. investment, ${ }^{\text {a) }}$ Valuation including effect of investment, ${ }^{\text {b) }}$ baseline: round 1-4,

c) baseline: block 4 (block 2 for COMP_FIX treatment), ${ }^{\text {d) }}$ COMP_FIX treatment had only 2 blocks, ${ }^{\text {e) }}$ no PWYW entry in block 3 of COMP_FLEX treatment,

bold coeff.: sig. at $5 \%$ level

TABLE 2.-PWYW: Regression on Prices Paid

It is important to note that there is a lot of heterogeneity in the data. Some buyers make large payments even in the last round of the market, but some also behave selfishly. In fact, $12 \%$ of the subjects pay a price of zero in more than $80 \%$ of all periods in which they buy the PWYW product. On the other hand, $26.4 \%$ of the subjects pay positive prices in more than $80 \%$ of all periods. Furthermore, $14.4 \%$ of the subjects pay positive prices in the first three rounds of a market and nothing in the last round, a clear indication that they pay only to keep the seller in the market.

To disentangle the effects of outcome-based reciprocity (i.e., P1a) from intention-based reciprocity (i.e., P1b), we compare the base treatment with the exogenous investment treatment. As outlined in section 3, for two of the sessions of the base treatment, we conducted two sessions with exogenous investments that matched the seller's behavior in the base treatment. Because sellers in the exogenous investment treatment did not determine their own investment, buyers have no reason to reciprocate and should pay less than in the same situation of the base treatment. By comparing prices paid in the base treatment to the prices paid in the exogenous investment treatment, we can thus test directly whether intention-based reciprocity matters.

We find that mean prices do not significantly differ between the base and the (matched) exogenous investment treatment: the average price paid in the base treatment is not significantly different compared to the average price in the exogenous investment treatment (paired t-test: $\mathrm{p}>.1, \mathrm{df}=452$ ). Thus intention-based reciprocity does not have an effect in our experiments.

Result 2: The positive prices paid with PWYW are consistent with outcome-based social preference such as altruism and inequity aversion and with strategic behavior of self-interested 
buyers paying positive prices to keep the seller in business. The data support predictions P1a and P1c. Intention-based reciprocity (P1b) does not affect payments in our experiments.

\subsection{Market Penetration}

Our second prediction is that PWYW achieves maximal market penetration. However, even though all buyers can get the product for free, not all of them necessarily buy the product under PWYW. Some buyers might feel uneasy about taking a product without knowing what the appropriate price is. Also, buyers whose valuation for the product is smaller than the seller's production cost might abstain from buying the product because the transaction is inefficient. Our next result shows the conditions under which these worries are warranted:

Result 3: When the PWYW seller is the only seller in the market, almost all buyers buy his product. However, when a competing seller is offering posted prices, $10 \%$ to $25 \%$ of buyers buy at the posted price or not at all.

Support for Result 3 is provided in Tables 1 and 3. In the base treatment, $96.7 \%$ of the buyers buy the product, compared with 96.2\%; in the exogenous investment treatment. The logistic regression reported in Table 3 shows that concerns about efficiency resulted in the few cases in which buyers did not buy. The probability of buying significantly increases with the buyer's valuation and decreases with the seller's production costs. This finding is consistent with outcome-based models of social preferences.

\begin{tabular}{|c|c|c|c|c|c|}
\hline Treatment & $\begin{array}{c}\text { (1) } \\
\text { BASE }\end{array}$ & $\begin{array}{c}\left(\mathbf{1}^{\prime}\right) \\
\text { BASE Match }\end{array}$ & $\begin{array}{c}(2) \\
\text { EX. INVEST }\end{array}$ & $\begin{array}{c}\text { (3) } \\
\text { COMP_FIX }\end{array}$ & $\begin{array}{c}(4) \\
\text { COMP_FLEX }\end{array}$ \\
\hline Buyer valuation $^{\text {a) }}$ & $\mathbf{0 . 6 3}(0.14)$ & $\mathbf{0 . 4 4}(0.14)$ & $\mathbf{0 . 2 5}(0.07)$ & $\mathbf{- 0 . 0 8 ( 0 . 0 2 )}$ & $-0.30(0.16)$ \\
\hline Prod & .72 & ) & -0.4 & -0.30 & $0.61)$ \\
\hline PWY & $-0.78(0.71)$ & -1.08 & $-1.72(1.16)$ & & \\
\hline Diff. Seller invest. & & & & $4.56(0.49)$ & $\mathbf{6 . 5 5}(2.83)$ \\
\hline Last ro & $1.56(1.05)$ & $1.70(1.60)$ & $0.10(0.84)$ & $0.63(0.38)$ & \\
\hline Block1 (DV) ${ }^{\mathrm{d})}$ & $0.43(0.78)$ & 0.13 & -0.03 & -0.20 & $-3.03(2.44)$ \\
\hline Block & $-0.08(0.96)$ & $0.37(1.46)$ & $0.15(0.81)$ & f) & $-1.06(1.62)$ \\
\hline Bloc & -0.61 & -0.84 & -0.48 & & \\
\hline PP ask price & & & & $\mathbf{0 . 6 4}(0.11)$ & $-0.56(0.41)$ \\
\hline$\overline{\text { No. } 0}$ & 430 & 165 & 249 & 589 & 63 \\
\hline No. of Subjec & 25 & 10 & 15 & 63 & 14 \\
\hline \multicolumn{6}{|c|}{$\begin{array}{l}\text { Notes: The dependent variable is } 1 \text { if the subject bought from a PWYW seller and } 0 \text { otherwise; only observations in which } \\
\text { the seller entered the market are included. Treatment }\left(1^{\prime}\right) \text { : base treatment, only sessions matched to exogenous investment, } \\
\text { FE regression with subject-specific fixed effects (standard errors in parentheses). Only subjects included with } 0 \text { and } 1 \text { for } \\
\text { dependent var. }{ }^{\text {a }} \text { Valuation including effect of investment. }{ }^{\text {b) }} \text { Difference between the dummy variables for the investment } \\
\text { decision of the PWYW seller and the PP seller. }{ }^{\text {c) }} \text { Baseline: round } 1-4 .{ }^{\text {d) }} \text { Baseline: block } 4 \text { (block } 2 \text { for COMP_FIX } \\
\text { treatment), }{ }^{\text {e }} \text { Last period perfectly predicts entry (all buy at PWYW if round } 5=1 \text { ), dropped; }{ }^{f)} \text { COMP_FIX treatment had } \\
\text { only } 2 \text { blocks, }{ }^{\text {g) }} \text { no PWYW entry in block } 3 \text { of COMP_FLEX treatment, bold coeff.: sig. at } 5 \% \text { level. }\end{array}$} \\
\hline
\end{tabular}

TABLE 3.-—Logistic Regression on PWYW Buying Decision 
However, in the two competition treatments, far fewer buyers choose to buy from the PWYW seller. In COMP_FIX, only $73.9 \%$ of buyers do so; in COMP_FLEX (where PWYW was rarely offered), that number is $89.7 \%$. Note first that of the 192 buyers who do not buy from a PWYW seller in COMP_FIX and COMP_FLEX, only five do not buy at all. The remaining 187 do buy from a PP seller. However, this preference for PP could be driven by the fact that in some cases, the PWYW seller did not invest while the PP seller did. In fact, the logistic regressions (3) and (4) of Table 3 confirm that the difference between the PWYW seller's investment and the PP seller's investment has a highly significant effect on the buying decision. But even if we restrict attention to the 714 cases in COMP_FIX and COMP_FLEX in which a PWYW seller and a PP seller who both invested face each other, we find that buyers bought in 117 cases (16.4 percent) from the PP seller-even though they could have gotten the product for free from the PWYW seller. ${ }^{9}$ Thus a significant fraction of buyers prefers to buy from a traditional PP seller. Note that buyers choose the PP seller less often as the price becomes higher. Regression (3) in Table 3 shows that if the PP price increases in COMP_FIX, buyers become significantly more likely to opt for PWYW. ${ }^{10}$

Thus we find only partial support for prediction P2. PWYW achieves (almost) full market penetration under monopolistic conditions, but not if a competing seller is offering posted prices. But even under competitive conditions, PWYW can be more attractive than giving away the product for free, because it does generate positive revenues.

\subsection{Competition}

Predictions P3 and P4 concern the effects of PWYW as a competitive strategy. P3 predicts that PWYW drives out traditional PP sellers because a PWYW offer undercuts any positive posted price, and thus all consumers will choose the PWYW seller. Furthermore, if only (two) PWYW sellers compete, P4 predicts that PWYW softens competition (compared to a situation with one or two PP sellers present) because no prices exist with which to compete. Our experimental results clearly reject the first prediction and offer (weak) support for the second.

Result 4: (a) A significant fraction of up to $25 \%$ of buyers shop with the PP seller if a PWYW seller is available. Furthermore, buyers pay significantly lower voluntary prices to the PWYW seller if a competing PP seller is present than if the PWYW seller is a monopolist.

(b) If a PWYW seller is in the market, a competing seller makes higher profits if he also uses PWYW than if he chooses PP. However, two PWYW sellers facing each other make lower

\footnotetext{
${ }^{9}$ A chi-square test comparing the percentage of buyers who bought from those PWYW sellers (who invested) in the base and in the COMP_FIX treatment shows the difference is highly significant (Pearson chi2 $(1)=223.9164, p=0.000)$.

${ }^{10}$ The effect of the posted price is not significant in COMP_FLEX, but here we have rather few observations because sellers choose to use the PWYW pricing method in only $35 / 240=14.6 \%$ of all cases.
} 
profits than two competing PP sellers. When offered a choice, the large majority (85\%) of sellers choose posted prices.

As seen in section 4.2, PWYW does not drive PP sellers out of the market, but a significant minority of buyers prefers buying from a PP seller. The presence of a competing PP seller not only takes away some customers from the PWYW seller, it also reduces the price that PWYW buyers are willing to pay voluntarily. Comparing the average prices paid in the monopoly treatments (base and exogenous investment) to the average PWYW prices paid in the competition treatments, the latter ones are significantly smaller. ${ }^{11}$ Including the price charged by the PP seller in the regression on prices paid (see Table 4), a reduction of the PP price significantly decreases prices paid to the PWYW seller. ${ }^{12}$ Customers are reluctant to pay more to a PWYW seller than what is charged by a PP seller for exactly the same product. Thus the presence of a PP seller exerts a strong negative externality on the PWYW seller.

\begin{tabular}{|c|c|c|}
\hline Treatment & $\begin{array}{c}\text { (3) } \\
\text { COMP_FIX }\end{array}$ & $\begin{array}{c}\text { (4) } \\
\text { COMP_FLEX }\end{array}$ \\
\hline Intercept & $-0.50(0.47)$ & $\mathbf{- 0 . 9 3 ( 0 . 4 0 )}$ \\
\hline Buyer valuation $^{\text {a) }}$ & $\mathbf{0 . 1 2}(0.02)$ & $\mathbf{0 . 0 9}(0.02)$ \\
\hline Production cost & $\mathbf{0 . 2 0}(0.09)$ & $0.09(0.09)$ \\
\hline Seller investment (DV) & $0.10(0.40)$ & $0.39(0.34)$ \\
\hline PP ask price & $\mathbf{0 . 1 5}(0.05)$ & $\mathbf{0 . 3 2}(0.08)$ \\
\hline Last round (DV) ${ }^{\text {b) }}$ & $-0.11(0.15)$ & $0.06(0.38)$ \\
\hline Block1 (DV) ${ }^{\mathrm{c})}$ & $\mathbf{0 . 4 1}(0.15)$ & $-0.29(0.29)$ \\
\hline Block2 (DV) ${ }^{\mathrm{c})}$ & d) & $-0.48(0.29)$ \\
\hline No. of Obs. & 492 & $120^{\mathrm{e})}$ \\
\hline R-squared & 0.244 & 0.446 \\
\hline No. of Subjects & 72 & 36 \\
\hline \multicolumn{3}{|c|}{$\begin{array}{l}\text { Notes: The dependent variable is measured in the experimental currency; only observations } \\
\text { of buyers buying are included. FE regression with subject-specific fixed effects (robust } \\
\text { standard errors in parentheses). }{ }^{\text {a) }} \text { Valuation including effect of investment, }{ }^{\text {b }} \text { baseline: round } \\
1-4,{ }^{\text {c) }} \text { baseline: block } 4 \text { (block } 2 \text { for COMP_FIX treatment), }{ }^{\text {d) }} \text { COMP_FIX treatment had } \\
\text { only } 2 \text { blocks; no PWYW entry in block } 3 \text { of COMP_FLEX treatment, }{ }^{\text {e) }} \text { only cases with one } \\
\text { PWYW seller and one PP seller included, bold coeff.: sig. at 5\% level. }\end{array}$} \\
\hline
\end{tabular}

TABLE 4.-PWYW: Regression on Prices Paid (incl. PP ask price)

Which selling method should a seller choose? To answer this question, we have to restrict attention to the COMP_FLEX treatment. In COMP_FLEX, buyers know the PWYW seller uses the PWYW strategy

\footnotetext{
${ }^{11}$ A two-sided rank-sum test (Mann-Whitney) confirms that mean prices per session differ significantly ( $\left.\mathrm{p}<0.01\right)$. At the individual level, this effect is (of course) much stronger $(\mathrm{t}=8.79)$.

${ }^{12}$ Table 2 did not include the PP price to have the same predictors for all treatments. Table 4 includes the PP price and shows the regression results for the two competition treatments. Please note that the number of observations is lower in the regression for the (4) COMP_FLEX treatment (compared to Table 2), because we have no observations for PP price if both sellers chose PWYW.
} 
voluntarily. Thus buyers may react differently compared to a situation in which they know the seller is forced to offer PWYW. ${ }^{13}$ To be on the safe side, we therefore restrict attention to COMP_FLEX (but Table 5 also reports the results of COMP_FIX).

\begin{tabular}{|c|c|c|c|c|}
\hline Treatment & & MP_FLEX & & COMP_FIX \\
\hline Market Structure & PWYW vs PWYW & PP vs PP & PWYW vs PP & PWYW vs PP ${ }^{a)}$ \\
\hline Average PWYW price paid ${ }^{\text {b) }}$ & 2.08 & - & 1.54 & 2.33 \\
\hline Average PP price set & - & 3.97 & 3.96 & 4.39 \\
\hline Average PP price paid ${ }^{\mathrm{b})}$ & - & 3.45 & 4.47 & 3.99 \\
\hline Average PP markup set & - & 2.27 & 2.56 & 2.91 \\
\hline Average PP markup paid ${ }^{\text {b) }}$ & - & 1.78 & 2.94 & 2.68 \\
\hline Average PWYW market share ${ }^{c)}$ & 0.5 & - & 0.88 & 0.74 \\
\hline Average profit of PWYW seller & 2.42 & - & -0.70 & 1.83 \\
\hline Average profit of PP seller & - & 3.20 & 0.87 & 2.44 \\
\hline Number of markets & 6 & 91 & 23 & 111 \\
\hline
\end{tabular}

TABLE 5.- Summary statics for different market structure with competition

We find that if both sellers choose PWYW, competition is relaxed. With two PWYW sellers, buyers pay on average 2.08, whereas they paid only 1.54 if the PWYW seller faces a PP seller (see Table 5). If both sellers choose PWYW, each of them makes an average profit of 2.4, whereas a PP seller facing a PWYW seller makes an average profit of only 0.9. Thus, it is a Nash equilibrium that both sellers choose PWYW. This finding offers some support for the second part of prediction 3. However, it is also a Nash equilibrium that both sellers choose posted prices. In this case, each seller makes an average profit of 3.2 while he receives only -0.7 if he deviates to PWYW. The PP equilibrium Pareto dominates the PWYW equilibrium, although the difference in profits is not statistically significant. However, if one PP seller faces a PWYW seller, the PP seller makes a higher profit (0.9) than the PWYW seller (-0.7). This profit advantage may have induced the large majority of subjects $(85 \%)$ to opt for posted prices.

\section{Conclusions}

What are the implications of our experimental study for Pay What You Want in the real world? Many differences exist, of course, between a laboratory experiment and the interaction of buyers and sellers in a real market. In our experiments, the interaction between buyers and sellers is computerized and completely anonymous, no scope for communication or personal interaction between the subjects is present, the product

\footnotetext{
${ }^{13}$ The effect could go in both directions. A buyer could voluntarily pay more if the seller is forced to offer PWYW because he pities the seller, or he could pay more to a seller who voluntarily offers PWYW in order to reciprocate. PWYW prices end up being higher in the COMP_FIX treatment, but the difference is not statistically significant.
} 
is fictitious and reduced to its monetary value for the buyer and the seller, and no other people observe how much the buyer is paying. All of these factors enable a buyer to pay nothing, and bias our results against the viability of PWYW. Thus, if we observe that certain factors make PWYW more profitable in the experiment, then these factors are likely to have a positive impact in the real world as well. On the other hand, if an effect is not significant in the lab, we should be much more careful to conclude that this factor is irrelevant under all circumstances.

Our first result shows that the larger the buyers' valuation and the higher the seller's cost, the more that buyers pay. This finding is consistent with models of outcome-based social preferences such as altruism or inequity aversion. This result suggests PWYW is likely to be a more successful strategy for small shops and non-profit organizations than for large and highly profitable corporations. Furthermore, because an increase in production costs by $\$ 1$ causes buyers to increase their voluntary payment by only 10 to 20 cents, PWYW is best suited for products with low marginal costs that create a high value for customers, such as some digital products, museum or church visits, or tickets for the cinema or for cultural events.

Our first result also suggests buyers do not reciprocate to the investment of the seller per se; rather, they react predominantly to the value the investment creates. This negative result may be due to the anonymity of the interaction in the lab. If the buyer and the seller interact face to face, a friendly seller who makes an effort to deliver the best possible quality will be more likely to induce a buyer to pay more, either by triggering reciprocity or by shaming him to pay an appropriate amount. This additional force might explain why some restaurants or other service providers manage to survive with PWYW. However, our result suggests that with anonymous interaction, a costly investment is not enough to increase voluntary payments. Buyers are willing to pay more only if the investment has a large effect on their valuations.

Furthermore, we have seen that a significant fraction of buyers pay for strategic reasons because they want to keep the seller in business. This finding suggests a neighborhood shop or restaurant is likely to receive higher payments than a seller dealing with his customers only once.

Our second result shows that PWYW can be an attractive marketing strategy to achieve full market penetration, but only if no competing sellers of the same product are in the market. In this case, almost all buyers with a positive valuation for the product get it, and most of them contribute at least some positive amount to cover the production cost. This broad extent of buying can explain why companies that want to maximize sales either for intrinsic reasons (such as museums, churches, and other NPOs) or to sell complementary products (such as the rock band "Radiohead") often prefer PWYW to giving away the product for free. However, if competing sellers are offering similar products, this argument is less convincing. In this case, a significant fraction of buyers chooses a PP seller, and the price the PP seller charges reduces the voluntary payments made to the PWYW seller. Furthermore, competition does away with the need to pay more in order to keep the PWYW seller in business. 
Finally, our third result shows that PWYW is less successful as a competitive strategy. First of all, it fails to drive competing PP sellers out of the market. Some customers will always prefer not to buy from a PWYW seller but rather at a posted price. Second, if the competing PP seller stays in the market, buyers reduce their payments to the PWYW seller. Few buyers pay more to the PWYW seller than what they would have to pay the PP seller for the same product. Finally, even if both sellers offer PWYW, they make lower profits than if both sellers were to use posted prices. However, PWYW does have the positive effect of reducing competition. If both sellers use PWYW, they are both better off than in a situation in which one of them chooses PWYW and the other chooses PP. Thus, if the other seller is committed to using PWYW, then for the second seller to use PWYW as well can be optimal. For example, if a museum uses PWYW, then another museum competing for the same visitors may want to do so as well.

Our results also raise some interesting new questions for future research. First, we observe that a significant minority of buyers prefers to buy at posted prices rather than from a PWYW seller, but we do not understand why. Is it the mental cost of coming up with the "appropriate" price that should be paid in this situation, or is it rather that this behavior is driven by concerns for self-image and identity, as suggested by Gneezy et al. (2012)? What can be done to increase the acceptance of PWYW? Second, some but not all PWYW sellers make price "suggestions." Analyzing the benefits and costs of this strategy would be interesting. Finally, we find that under monopolistic conditions, PWYW achieves almost full market penetration while still yielding positive revenues (or even profits). Thus, directly comparing PWYW to the alternative strategy of giving away samples for free, as well as to so-called "freemium" pricing models, would be interesting. Which of these marketing strategies should be applied under which circumstances? These are important questions for future research. 


\section{References}

Andreoni, J., J. Miller. 2002. Giving According to GARP: An Experimental Test of the Consistency of Preferences for Altruism. Econometrica. 70(2) 737-753.

Berg, J., J. Dickhaut, K. McCabe. 1995. Trust, Reciprocity, and Social History. Games and Economic Behavior. 10(1) 122-42

Bolton, G.E., E. Katok, A. Ockenfels. 2004. How Effective Are Electronic Reputation Mechanisms? An Experimental Investigation. Management Science. 50(11) 1587-1602.

Bolton, G.E., A. Ockenfels. 2000. ERC: A Theory of Equity, Reciprocity, and Competition. American Economic Review. 90(1) 166-193.

Brown, M., A. Falk, E. Fehr. 2004. Relational Contracts and the Nature of Market Interactions. Econometrica. 72(3) 747-780.

Chen, X., O. Koenigsberg, and Z.J. Zhang. 2010. Pay as You Wish Pricing, mimeo.

Dufwenberg, M., G. Kirchsteiger. 2004. A theory of sequential reciprocity. Games and Economic Behavior. 47(2) 268-298.

Falk, A., U. Fischbacher. 2006. A theory of reciprocity. Games and Economic Behavior. 54(2) 293-315.

Fehr, E., A. Klein, K.M. Schmidt. 2007. Fairness and Contract Design. Econometrica. 75(1) 121-154.

Fehr, E., K.M. Schmidt. 1999. A Theory of Fairness, Competition, and Cooperation. The Quarterly Journal of Economics. 114(3) 817-868.

Fehr, E., K.M. Schmidt. 2006. The Economics of Fairness, Reciprocity and Altruism - Experimental Evidence and New Theories. Kolm, S-C., J.M. Ythier (eds.) Handbook on the Economics of Giving, Reciprocity and Altruism, Vol. 1, Amsterdam (2006): Elsevier, 615-691.

Fischbacher, U. 2007. z-Tree: Zurich toolbox for ready-made economic experiments. Experimental Economics. 10(2) 171-178.

Gautier, P.A., B. van der Klaauw, B. 2012. Selection in a field experiment with voluntary participation. Journal of Applied Econometrics. 27(1) 63-84.

Gneezy, A., U. Gneezy, L.D. Nelson, A. Brown. 2010. Shared Social Responsibility: A Field Experiment in Pay-What-You-Want Pricing and Charitable Giving. Science. 329(5989) 325-327.

Gneezy, A., U. Gneezy, G. Riener, L.D. Nelson. 2012. Pay-what-you-want, identity, and self-signaling in markets. Proceedings of the National Academy of Sciences, forthcoming. 
Greiner, B. 2004. The Online Recruitment System ORSEE - A Guide for the Organization of Experiments in Economics. University of Cologne, Cologne, Germany.

Kim, J.-Y., M. Natter, M. Spann. 2009. Pay What You Want: A New Participative Pricing Mechanism. Journal of Marketing. 73(1) 44-58.

Kim, J.-Y., M. Natter, M. Spann. 2010. Kish: Where Customers Pay As They Wish. Review of Marketing Science. 8(2) Artricle 3.

Kreps, D.M., P. Milgrom, J. Roberts, R. Wilson. 1982. Rational cooperation in the finitely repeated prisoners' dilemma. Journal of Economic Theory. 27(2) 245-252.

León, F.J., J.A. Noguera, J. Tena-Sánchez. 2012. How much would you like to pay? Trust, reciprocity and prosocial motivations in El trato. Social Science Information. 51(3) 389-417.

Mak, V., R. Zwick, A.R. Rao. 2010. "Pay what you want" as a profitable pricing strategy: Theory and experimental evidence. University of Cambridge, Cambridge, UK.

Rabin, M. 1993. Incorporating Fairness into Game Theory and Economics. The American Economic Review. 83(5) 1281-1302.

Regner, T., J.A. Barría. 2009. Do consumers pay voluntarily? The case of online music. Journal of Economic Behavior and Organization. 71(2) 395-406.

Regner, T. 2009. Social preferences? Google answers! Jena Economic Research Papers in Economics 2009035. University of Jena, Jena, Germany.

Riener G., C. Traxler. 2012. Norms, moods and free lunch: Longitudinal evidence on payments from a PayWhat-You-Want restaurant. Journal of Socio-Economics. 41(4) 476-483. 


\section{Appendix: Experimental Instructions}

\section{A1. Base Treatment}

\section{Roles}

In the experiment there are two roles, which we denote as buyer and seller. Your role will be assigned to you randomly and will stay the same throughout the experiment. On the first screen you will be informed about which role was assigned to you.

\section{Decisions and procedures}

The experiment consists of 20 periods, which are separated into four blocks of 5 periods each. You are asked to make the same type of decisions in each period.

At the start of each block, every seller will be connected to three randomly selected buyers. Each buyer is only connected to one seller. In every period, each seller can sell one unit of his product to each of his buyers.

The seller sells his product with the "Pay What You Want" pricing mechanism. This means that each buyer can decide how much he wants to pay for the product. The seller has to sell the product to the buyer in any case, even if the buyer pays zero and the seller incurs a loss.

A block ends after five periods and every seller will be matched with three other randomly selected buyers for the next block.

Each period consists of two stages:

- In stage one of each period, the seller decides whether he wants to offer a product in this period or not. If he does not want to sell anything, his profit and the profit of the three buyers assigned to him is zero and the period ends. If the seller offers the product, he needs to decide on whether he wants to invest in the quality of his product or not. Investment in quality costs 2 but doubles buyers' valuations. Next, the seller learns his unit production cost for his product. These costs are between 0 and 4 points and are randomly determined in every period.

- At the second stage buyers learn their valuations of the product. This denotes the amount of money the buyer receives at the end of the experiment for the product in case he bought it. Their valuation depends on whether the seller invested in the quality of his product or not:

- If the seller did not invest in the quality of his product, buyer's valuation is either 2,6 , or 10 points. The buyer's valuation is randomly selected from these values. Please note that it may happen that several buyers have the same valuation.

- If the seller did invest in the quality of this product, valuations are doubled and are either 4, 12 , or 20 .

The buyers learn whether their assigned seller invested in product quality or not, and which costs accrue to the seller for investment and the production of the product. Finally, buyers decide whether they want to buy and how much to pay voluntarily. Every amount between 0 and 20 points is possible.

+ Details on the calculation of seller and buyer profit as well as several control questions. 


\section{A2. COMP_FLEX Treatment}

\section{Roles}

In the experiment are two roles, which we denote as buyer and seller. Your role will be assigned to you randomly and will stay the same throughout the experiment. On the first screen you will be informed about which role was assigned to you.

\section{Decisions and procedures}

The experiment consists of 20 periods, which are separated into four blocks of 5 periods each. You are asked to make the same type of decisions in each period.

At the start of each block, two sellers will be connected to six randomly selected buyers. In every period, each buyer can buy at most one unit of the good from one of the two sellers.

In every block, each seller can decide whether he wants to sell his product with a posted price or via the "Pay What You Want" pricing mechanism. If the seller sets a posted price, a buyer who wants to buy from him has to pay this price. If the seller uses "Pay What You Want" pricing, each buyer can decide how much he wants to pay for the product. The seller has to sell the product to the buyer in any case, even if the buyer pays zero and the seller incurs a loss.

A block ends after five periods. Then again two randomly matched sellers will be matched with six randomly selected buyers for the next block.

Each period consists of four stages:

- At stage one of each period, the seller decides whether he wants to offer a product in this period or not and whether he wants to sell it for a posted price or via "Pay What You Want" pricing. If he does not want sell anything, his profit is zero and the period ends for him.

- At stage two, an active seller learns whether the other seller offers the product in this period and which pricing mechanism he chose. Then, each active seller has to decide whether he wants to invest in the quality of his product or not. Investment in quality costs 2 points and doubles buyers' valuations.

- At stage three, the seller learns whether the other seller invested in the quality of the product. He also learns the unit production cost for his product (production costs are the same for both sellers). These costs are between 0 and 4 points and are randomly determined in every period. The posted-price seller stets his price.

- At stage four, buyers learn which sellers are active on the market and which pricing mechanism they chose, which seller invested and what buyers' valuations are for the products of the sellers.

The valuation denotes the amount of money the buyer receives at the end of the experiment for the product in case he bought it. The valuation depends on whether the seller invested in the quality of his product or not:

$\circ$ If the seller did not invest in the quality of his product, buyer's valuation is either 2,6 , or 10 points. The buyer's valuation is randomly selected from these values. Note that it may happen that several buyers have the same valuation.

- If the seller did invest in the quality of this product, valuations are doubled and either 4,12 , or 20 .

Further, buyers learn which costs sellers accrue for investment and the production of the product. Finally, buyers decide whether and from which seller they want to buy. If they buy from the postedprice seller, they have to pay his price. If they buy from the Pay What You Want seller, buyers decide how much they pay for the product. Every amount between 0 and 20 points is possible.

+ Details on the calculation of seller and buyer profit as well as several control questions. 